Check for updates

Cite this: RSC Adv., 2017, 7, 20309

\title{
Design structure for CePr mixed oxide catalysts in soot combustion $\uparrow$
}

\author{
Lijia Fan, Kang Xi, Ying Zhou, * Qiulian Zhu, Yinfei Chen and Hanfeng Lu (DD *
}

Four CePr mixed oxides with different structures were designed and synthesized using a solid-phase grinding method: a uniform solid solution of $\mathrm{Ce}$ and $\operatorname{Pr}(\mathrm{CePr}-\mathrm{NN}), \mathrm{Pr}_{6} \mathrm{O}_{11}$-coated $\mathrm{CeO}_{2}(\mathrm{CePr}-\mathrm{NO}), \mathrm{CeO}_{2}$-coated $\mathrm{Pr}_{6} \mathrm{O}_{11}(\mathrm{CePr}-\mathrm{ON})$, and particle packing of $\mathrm{CeO}_{2}$ and $\mathrm{Pr}_{6} \mathrm{O}_{11}(\mathrm{CePr}-\mathrm{OO})$ were obtained, and characterized by XRD, $\mathrm{H}_{2}$-TPR, TEM and TG. The results show that CePr-NN exhibits the best low temperature catalytic activity among the CePr catalysts. $\mathrm{CeO}_{2}$ is the major active phase on the surface of the CePr catalysts, and the use of $\mathrm{Pr}_{6} \mathrm{O}_{11}$ as the framework maintains the thermal stability of the CePr composite oxide. Moreover, both the oxygen storage capacity and mobility of the active oxygen of the catalyst were improved with the incorporation of $\mathrm{Pr}$ into $\mathrm{CeO}_{2}$, resulting in a higher combustion rate. The "molten state" which appeared during the preparation when nitrate was used as the precursor, plays a significant role in the migration of $\mathrm{Ce}$ and $\mathrm{Pr}$, and is the premise of forming different structures of solid solution or coating structure.

Received 26th December 2016 Accepted 17th March 2017

DOI: $10.1039 / \mathrm{c} 6 \mathrm{ra} 28722 \mathrm{k}$

rsc.li/rsc-advances and $\operatorname{Pr}_{6} \mathrm{O}_{11}$ are fluorite-like. In addition, the $\mathrm{Ce}^{4+}$ ionic radius $(0.097 \mathrm{~nm})$ is considerably similar to that of $\operatorname{Pr}^{4+}(0.096 \mathrm{~nm})$, and all of the atoms can exist with the mixed oxidation states of $3+$ and $4+$ in CePr solid solution. CePr mixed oxides show better performance than other $\mathrm{CeO}_{2}$-based catalysts in soot combustion ${ }^{\mathbf{1 4 3 0 , 3 2 - 3 6}}$ with more active oxygen species and higher oxideion mobility, low-temperature activity, and thermal stability. ${ }^{37,38}$ However, to the best of our knowledge, few reports exist on how $\mathrm{Pr}$ penetrates into the $\mathrm{CeO}_{2}$ lattice and on the position distribution in the structure of the two metal elements, which are significantly important for the identification of the relationship between the structures and catalytic properties of CePr mixed oxides.

The preparation methods of $\mathrm{CeO}_{2}$-based catalysts mainly include coprecipitation, ${ }^{3,5,7,8,12,13,22,27,30,31,39}$ hydrothermal, ${ }^{\mathbf{4 0 - 4 2}}$ citric acid complex combustion, ${ }^{23}$ sol-gel, ${ }^{2,33,43,44,46-48}$ solution combustion, ${ }^{40,41}$ solid-state, ${ }^{26}$ impregnation, ${ }^{45}$ (inverse) microemulsion, ${ }^{25,32,35}$ and solid-phase grinding methods. ${ }^{34,35}$ Among them, the solid-phase grinding method is the easiest technique to control the positions of the metal atoms in the structure. Moreover, this method is effective for building catalysts with different structures. In this work, CePr mixed oxides with different structures were prepared using a solid-phase grinding method, using different precursors to control the positions of $\mathrm{Ce}$ and $\mathrm{Pr}$ in the bulk structure. The physical and chemical properties were investigated using thermogravimetry (TG), hydrogen temperature-programmed reduction $\left(\mathrm{H}_{2}\right.$-TPR), X-ray diffraction (XRD), and transmission electron microscopy (TEM), and associated with soot oxidation. The purpose of this work is to get an insight into the influence of the distribution of Ce and Pr in CePr catalysts on soot combustion performance.
College of Chemical Engineering, Zhejiang University of Technology, Hangzhou 310014, PR China. E-mail: wjfx@zjut.edu.cn; luhf@zjut.edu.cn; Tel: +86-571-88320767

$\dagger$ Electronic supplementary information (ESI) available. See DOI: $10.1039 / \mathrm{c} 6 \mathrm{ra} 28722 \mathrm{k}$ 


\section{Experimental}

\section{Catalyst preparation}

Sample pretreatment: $\mathrm{CeO}_{2}$ was prepared using an ammonia coprecipitation method, using the corresponding nitrate as the precursor and ammonia water as the precipitating agent. The required amount of $\mathrm{Ce}\left(\mathrm{NO}_{3}\right)_{3} \cdot 6 \mathrm{H}_{2} \mathrm{O}$ was dissolved in deionized water, and a suspension was achieved by dropwise addition of $1 \mathrm{M} \mathrm{NH}_{3} \cdot \mathrm{H}_{2} \mathrm{O}$ until the $\mathrm{pH}$ reached 9 to 10 . The precipitate obtained was isolated by filtration, washed three times with deionized water, and dried at $110{ }^{\circ} \mathrm{C}$ for $12 \mathrm{~h}$. Finally, the sample was calcined at $500{ }^{\circ} \mathrm{C}$ for $3 \mathrm{~h}$. Pure $\operatorname{Pr}_{6} \mathrm{O}_{11}$ was also prepared using the same coprecipitation method.

CePr mixed oxide catalysts were prepared by mixing the appropriate amounts of $\mathrm{Ce}\left(\mathrm{NO}_{3}\right)_{3} \cdot 6 \mathrm{H}_{2} \mathrm{O} / \mathrm{CeO}_{2}$ and $\operatorname{Pr}\left(\mathrm{NO}_{3}\right)_{3}$ $.6 \mathrm{H}_{2} \mathrm{O} / \mathrm{Pr}_{6} \mathrm{O}_{11}$ in an agate mortar, followed by calcination at $500{ }^{\circ} \mathrm{C}$ for $3 \mathrm{~h}$. The resulting mixtures were referred to as CePr$\mathrm{NN}\left(\mathrm{Ce}\left(\mathrm{NO}_{3}\right)_{3} \cdot 6 \mathrm{H}_{2} \mathrm{O}\right.$ and $\left.\mathrm{Pr}\left(\mathrm{NO}_{3}\right)_{3} \cdot 6 \mathrm{H}_{2} \mathrm{O}\right)$, CePr-NO $\left(\mathrm{Ce}\left(\mathrm{NO}_{3}\right)_{3}-\right.$ $\cdot 6 \mathrm{H}_{2} \mathrm{O}$ and $\left.\mathrm{Pr}_{6} \mathrm{O}_{11}\right)$, CePr-ON $\left(\mathrm{CeO}_{2}\right.$ and $\left.\operatorname{Pr}\left(\mathrm{NO}_{3}\right)_{3} \cdot 6 \mathrm{H}_{2} \mathrm{O}\right)$, and CePr-OO $\left(\mathrm{CeO}_{2}\right.$ and $\left.\operatorname{Pr}_{6} \mathrm{O}_{11}\right)$.

\section{Catalyst characterization}

The structural features of all of the catalysts were characterized by powder XRD. The XRD patterns were recorded on a diffractometer (ARL SCINTAG X'TRA) operated at $45 \mathrm{kV}$ and $30 \mathrm{~mA}$ using nickel-filtered $\mathrm{Cu}-\mathrm{K} \alpha$ radiation. Diffractograms were registered between $10^{\circ}$ and $80^{\circ}(2 \theta)$ with a $0.02^{\circ}$ step.

The specific surface areas of the samples were determined by $\mathrm{N}_{2}$ adsorption measured at $-196{ }^{\circ} \mathrm{C}$, using the BrunauerEmmett-Teller method and a micropore porosity analyzer (3Flex, Micromeritics, USA). The samples were pretreated under vacuum at $300{ }^{\circ} \mathrm{C}$ for $2 \mathrm{~h}$ prior to measuring.

The reducibility of the CePr catalysts was studied by performing $\mathrm{H}_{2}$-TPR experiments on a chemisorption analyzer (FINESORB-3010E, Fantai, China). The catalysts $(100 \mathrm{mg})$ were pretreated in a U-shaped quartz reactor at $200{ }^{\circ} \mathrm{C}$ for $1 \mathrm{~h}$ and subsequently cooled to $100{ }^{\circ} \mathrm{C}$ under air flow $\left(30 \mathrm{ml} \mathrm{min}{ }^{-1}\right)$. Then, the catalyst bed was subjected to a flow $\left(30 \mathrm{ml} \mathrm{min}^{-1}, 5 \%\right.$ $\mathrm{H}_{2}$ in $\mathrm{Ar}$ ) at $100^{\circ} \mathrm{C}$ for $20 \mathrm{~min}$, followed by heating at a constant rate $\left(10{ }^{\circ} \mathrm{C} \min ^{-1}\right)$ up to $750{ }^{\circ} \mathrm{C}$. Finally, the catalyst was cooled under an Ar flow ( $\left.30 \mathrm{ml} \mathrm{min}^{-1}\right)$. The hydrogen consumption was monitored using a thermal conductivity detector operating at $60{ }^{\circ} \mathrm{C}$ and $60 \mathrm{~mA}$.

The micro-morphology and actual composition of the CePr mixed oxides were determined using a HR-TEM (Tecnai G2 F30 S-Twin $300 \mathrm{kV}$, Philips-FEI, Netherlands) microscope-coupled EDS analyzer.

Raman spectra were acquired using a Raman spectrometer (HR 800 Lab RAM, Horiba Jobin Yvon, France) equipped with a $531.95 \mathrm{~nm}$ laser (frequency-doubled Nd:YAG, $20 \mathrm{~mW}$ ) and a charge-coupled device (CCD) detector (multichannel, air cooled). Approximately $8 \mathrm{~mW}$ laser light was focused on the central level of the horizontal FSCR to acquire Raman signals in the liquid phase.

$\mathrm{X}$-ray photoelectron spectroscopy was performed in order to identify the valence states and surface composition of the catalysts on a Kratos AXIS Ultra DLD spectrometer. The analysis system used a monochromatic $\mathrm{Al} \mathrm{K} \alpha(1486.6 \mathrm{eV}) \mathrm{X}$-ray source, and the pressure was kept below $5 \times 10^{-7}$ Torr. The $\mathrm{C} 1 \mathrm{~s}$ peak $(284.6 \mathrm{eV})$ was used to calibrate the binding energy $(\mathrm{BE})$.

\section{Catalytic activity measurement}

The catalytic activity for soot (Printex-U provided by Degussa) combustion of the CePr catalysts was studied in a TG analyzer (Netzsch STA 409PC, Germany). Soot-catalyst mixtures (catalyst: soot $=1: 10$ ) were ground in an agate mortar for $10 \mathrm{~min}$ to achieve a "tight contact" condition for obtaining the intrinsic activity of the catalysts. Oxidation experiments involved heating each mixture (approximately $10 \mathrm{mg}$ ) at a rate of $10{ }^{\circ} \mathrm{C} \min ^{-1}$ from $25{ }^{\circ} \mathrm{C}$ to $650{ }^{\circ} \mathrm{C}$ under a flow of $10 \% \mathrm{O}_{2}$ in $\mathrm{N}_{2}$ $\left(50 \mathrm{ml} \mathrm{min}^{-1}\right)$.

The catalytic activity was evaluated from three aspects: (a) the ignition temperature of the soot $\left(T_{\mathrm{i}}\right.$, the extrapolated starting point of the TG curve); (b) the temperature at the highest rate of soot oxidation ( $T_{\mathrm{m}}$, the maximum of the DTG curve); (c) the burnout temperature of the soot $\left(T_{\mathrm{f}}\right.$, the extrapolated ending point of the TG curve).

\section{Results and discussion}

\section{Structural design of the catalysts}

CePr catalysts with different structures were prepared from different precursors as designed. The structure of the CePr-NN catalyst is a uniform composition of Ce and Pr; CePr-NO is $\mathrm{Pr}_{6} \mathrm{O}_{11}$-coated $\mathrm{CeO}_{2}$, CePr-ON is $\mathrm{CeO}_{2}$-coated $\mathrm{Pr}_{6} \mathrm{O}_{11}$, and CePrOO is particle packing of $\mathrm{CeO}_{2}$ and $\mathrm{Pr}_{6} \mathrm{O}_{11}$ (Fig. 1). Furthermore, the corresponding TEM images and mapping results are shown in Fig. 1. Fig. 1 shows the difficulty in distinguishing the phases of Ce and Pr in CePr-NN, which may be attributed to the even distribution of $\mathrm{Ce}$ and $\mathrm{Pr}$, and results in the formation of a good solid solution structure. $\operatorname{Pr}_{6} \mathrm{O}_{11}$ exists on the surface of $\mathrm{CeO}_{2}$ in CePr-ON, whereas CePr-NO shows the opposite. The accumulation of $\mathrm{CeO}_{2}$ and $\operatorname{Pr}_{6} \mathrm{O}_{11}$ particles can be observed in CePr-OO. The X-EDS analysis of the catalysts (Table 1) and the elemental maps exhibiting the proportion and the distribution of Ce and Pr reveal that the structures of the catalysts that we prepared are similar to our design. These results provide clear evidence that nitrates are needed for preparing a CePr solid solution.

Presently, several researchers have been devoted to obtaining different structures of catalysts for soot combustion, because the structure plays an important role in catalytic activity. ${ }^{\mathbf{4 1 , 4 2}}$ This work shows that different combinations of precursors can build different structures of CePr catalysts using the simple solid-phase grinding method.

\section{Textural and structural characterization}

The XRD patterns of the catalysts are shown in Fig. 2. The lattice constants of $\mathrm{CeO}_{2}$ were calculated from the XRD patterns, based on Bragg's law, and the average crystallite sizes were calculated from the FWHM of the XRD peak using the Scherrer equation (Table 2). All of the diffraction peaks of $\mathrm{CeO}_{2}$ in the $2 \theta$ range of 

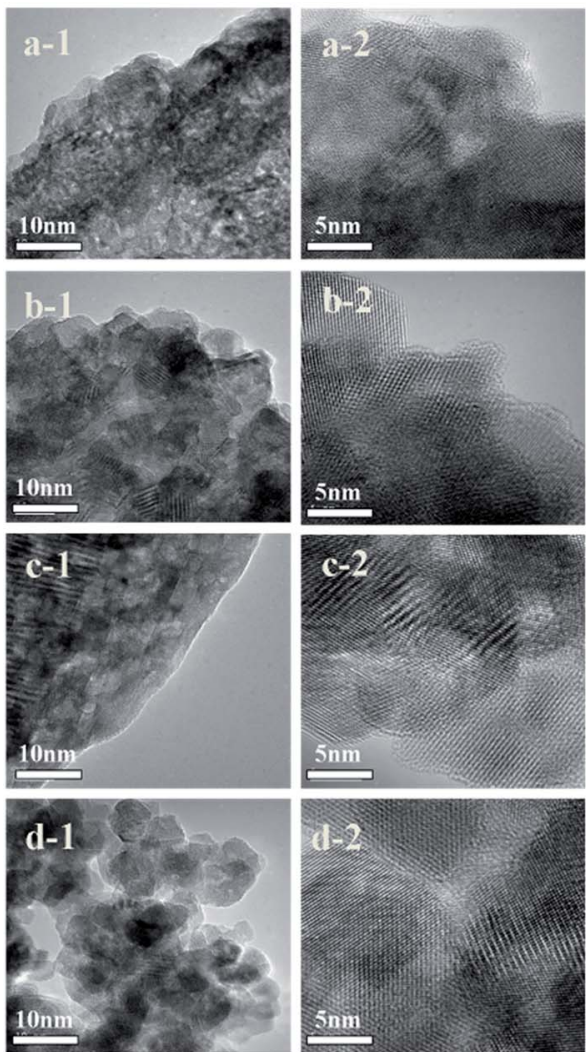

a

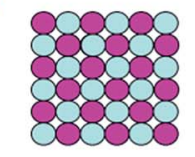

CePr-NN $\left(\mathrm{Ce}\left(\mathrm{NO}_{3}\right)_{3}+\operatorname{Pr}\left(\mathrm{NO}_{3}\right)_{3}\right)$

b

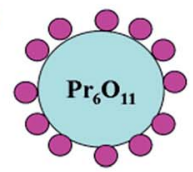

CePr-NO $\left(\mathrm{Ce}\left(\mathrm{NO}_{3}\right)_{3}+\operatorname{Pr}_{6} \mathrm{O}_{11}\right)$

c

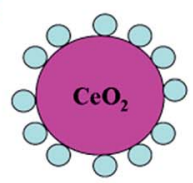

CePr-ON $\left(\mathrm{CeO}_{2}+\mathrm{Pr}\left(\mathrm{NO}_{3}\right)_{3}\right)$

d

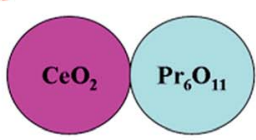

CePr-OO $\left(\mathrm{CeO}_{2}+\mathrm{Pr}_{6} \mathrm{O}_{11}\right)$
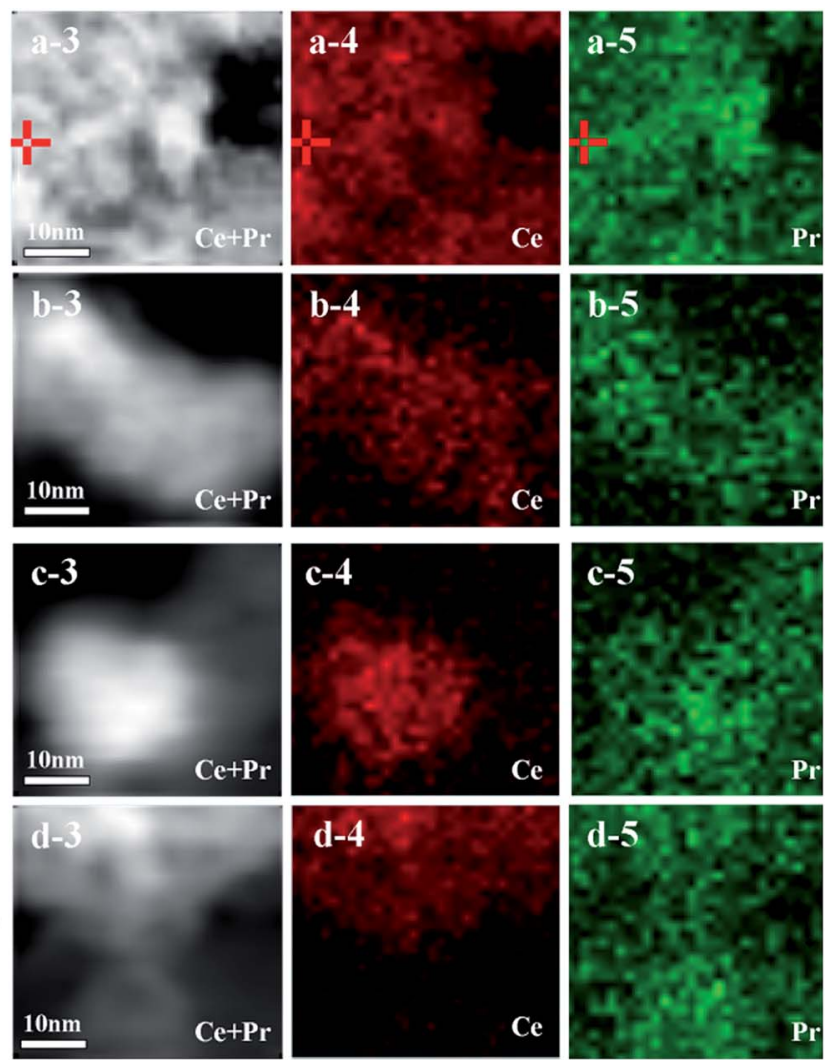

Fig. 1 Structure design and TEM images (mapping results) of the CePr mixed oxides. (a) CePr-NN; (b) CePr-NO; (c) CePr-ON; (d) CePr-OO.

$10^{\circ}$ to $80^{\circ}$ are remarkably near each other (Fig. 2(A)), because Ce and Pr have similar characteristics. However, a slight change in the diffraction peaks can be clearly observed in the enlarged version (Fig. 2(B)). For all of the CePr catalysts, the X-ray reflections shifted toward $2 \theta$ angles between $\mathrm{CeO}_{2}$ and $\mathrm{Pr}_{6} \mathrm{O}_{11}$, especially for CePr-NN. This finding suggests that a good solid solution structure is formed in CePr-NN, completely inserting Pr into the $\mathrm{CeO}_{2}$ crystal lattice, causing the increase of the lattice constant value. The broad diffraction peak in this region of CePr-OO does not suggest an external force during the oxide reaction. The $2 \theta$ value is the arithmetic mean of $\mathrm{CeO}_{2}$ and $\operatorname{Pr}_{6} \mathrm{O}_{11}$; thus, the CePr-OO structure may be particle packing of $\mathrm{CeO}_{2}$ and $\mathrm{Pr}_{6} \mathrm{O}_{11}$.

The characteristic diffraction peak of $\mathrm{CeO}_{2}$ in $\mathrm{CePr}-\mathrm{NO}$ and CePr-ON did not deviate from that of pure $\mathrm{CeO}_{2}$, indicating that $\mathrm{Pr}$ did not dissolve into the $\mathrm{CeO}_{2}$ lattice. The $2 \theta$ value and lattice constant of CePr-NO are relatively near those of $\mathrm{CeO}_{2}$, indicating that CePr-NO formed upon the interaction between $\mathrm{Ce}^{4+}$ and $\mathrm{Pr}_{6} \mathrm{O}_{11}$ during the $\mathrm{NO}_{3}{ }^{-}$decomposition process; thus, $\mathrm{CeO}_{2}$ was exposed on the $\operatorname{Pr}_{6} \mathrm{O}_{11}$ surface. However, CePr-ON is opposite to CePr-NO.

The lattice strain values of the catalysts are shown in Table 2 . It can be found that certain distortion occurred in the lattice structure of the catalyst, indicating that Pr inserts into the $\mathrm{CeO}_{2}$ crystal lattice. The greater the lattice strain value, the better the solid solution effect. It is thus reasonable to conclude that a good solid solution structure is formed in CePr-NN with the largest distortion.

In addition, doping with $\operatorname{Pr}$ is advantageous to obtain a reduction in crystallite sizes. However, the catalytic performance of the catalyst is not proportional to the specific surface area, as shown in Table 2. This demonstrated that the specific surface area is not the major factor in controlling the catalytic performance for soot combustion. There may be several other factors that do affect the catalytic performance, for example the number of contact points between the soot and catalyst

Table 1 Atomic composition of the CePr catalysts determined by X-EDS

\begin{tabular}{|c|c|c|c|c|c|c|c|}
\hline \multirow[t]{2}{*}{ CePr-NN } & $\mathrm{Ce}$ & 69.22 & 69.34 & CePr-ON & $\mathrm{Ce}$ & 41.67 & 41.80 \\
\hline & $\operatorname{Pr}$ & 30.77 & 30.77 & & $\operatorname{Pr}$ & 58.32 & 58.19 \\
\hline & $\operatorname{Pr}$ & 36.53 & 36.40 & & $\mathrm{Pr}$ & 46.43 & 46.29 \\
\hline
\end{tabular}



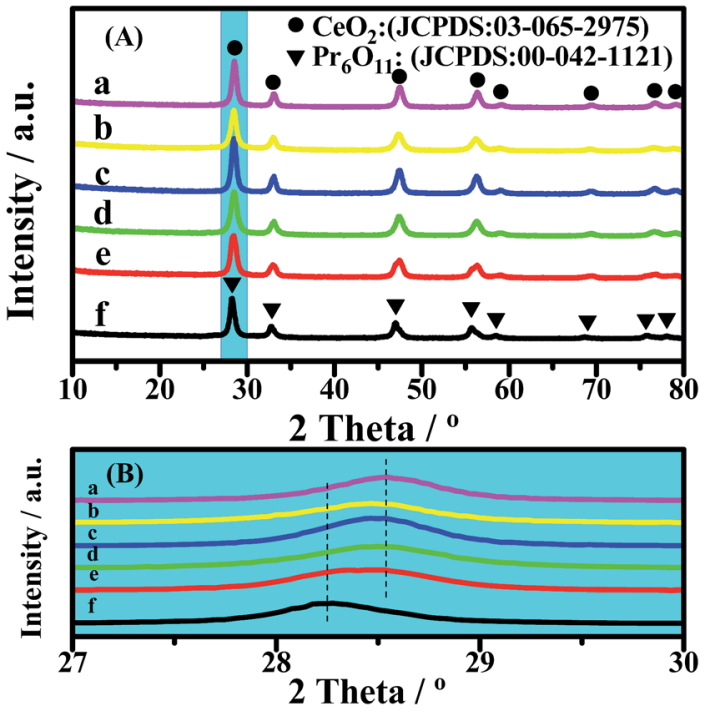

Fig. 2 XRD patterns of the CePr catalysts with different structures. (a) $\mathrm{CeO}_{2}$; (b) $\mathrm{CePr}-\mathrm{NN}$; (c) $\mathrm{CePr}-\mathrm{NO}$; (d) $\mathrm{CePr}-\mathrm{ON}$; (e) $\mathrm{CePr}-\mathrm{OO}$; (f) $\operatorname{Pr}_{6} \mathrm{O}_{11}$.

particles, because soot oxidation occurs on the triple-contact point of gas $\left(\mathrm{O}_{2}\right)$-solid (catalyst)-solid (soot). ${ }^{49,50}$ Agreeing with previous observations of Shangguan et al., ${ }^{51,52}$ we conclude that the specific surface area is not an important feature that influences the catalyst activity for soot combustion. The XRD results clearly confirm that the solid-phase grinding method used in this work is efficient in building different structures for CePr catalysts with different activities prepared from different precursors.

\section{Redox properties}

$\mathrm{H}_{2}$-TPR was performed to investigate the reducibility of the four kinds of CePr catalysts, the results of which are shown in Fig. 3. Pure $\mathrm{CeO}_{2}$ shows a wide reduction peak, which can be attributed to the reduction of $\mathrm{Ce}^{4+}$ to $\mathrm{Ce}^{3+}$. Pure $\operatorname{Pr}_{6} \mathrm{O}_{11}$ shows a large reduction peak below $200{ }^{\circ} \mathrm{C}$ but lost the reactive oxygen species before reaching the ignition temperature of soot combustion; thus, the light-off temperature increased to $406^{\circ} \mathrm{C}$. According to the literature,$^{53}$ the oxygen release capacity of the catalysts in the range of $200{ }^{\circ} \mathrm{C}$ to $400{ }^{\circ} \mathrm{C}$ is a significant factor in determining the soot combustion performance. Thus, the $\mathrm{H}_{2}$ consumption of the four kinds of CePr catalysts in this temperature range was

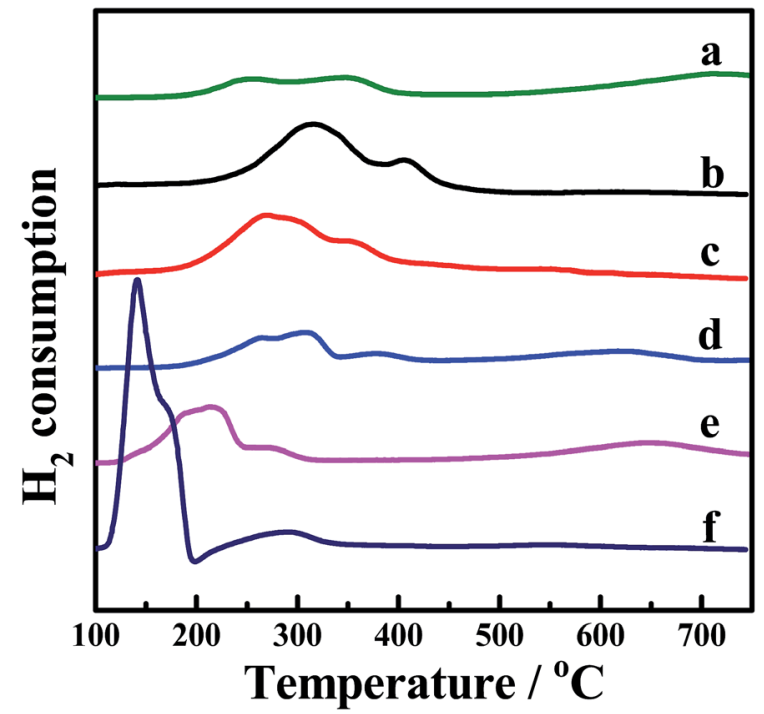

Fig. $3 \mathrm{H}_{2}$-TPR profiles of the CePr catalysts prepared from different precursors. (a) $\mathrm{CeO}_{2}$; (b) $\mathrm{CePr}-\mathrm{NN}$; (c) $\mathrm{CePr}-\mathrm{NO}$; (d) $\mathrm{CePr}-\mathrm{ON}$; (e) CePr-OO; (f) $\mathrm{Pr}_{6} \mathrm{O}_{11}$

Table $3 \quad \mathrm{H}_{2}$-TPR characterization and catalytic performance for soot combustion of CePr catalysts with different structures

\begin{tabular}{|c|c|c|c|c|c|}
\hline \multirow[b]{2}{*}{ Sample } & \multicolumn{2}{|c|}{$\begin{array}{l}\text { Temperature of peak and } \\
\mathrm{H}_{2} \text { consumption }\left(\mathrm{H}_{2}-\mathrm{TPR}\right)\end{array}$} & \multirow[b]{2}{*}{$T_{\mathrm{i}} /{ }^{\circ} \mathrm{C}$} & \multirow[b]{2}{*}{$T_{\mathrm{m}} /{ }^{\circ} \mathrm{C}$} & \multirow[b]{2}{*}{$T_{\mathrm{f}} /{ }^{\circ} \mathrm{C}$} \\
\hline & $T /{ }^{\circ} \mathrm{C}$ & $n\left(\mathrm{H}_{2}\right) /\left(\mathrm{mmol} \mathrm{g}^{-1}\right)$ & & & \\
\hline $\mathrm{CeO}_{2}$ & 257 & 0.0285 & 370 & 420 & 467 \\
\hline CePr-NN & 315 & 0.1421 & 370 & 413 & 443 \\
\hline CePr-NO & 276 & 0.1229 & 379 & 431 & 471 \\
\hline CePr-ON & 284 & 0.1005 & 411 & 482 & 517 \\
\hline CePr-OO & 203 & 0.0701 & 404 & 472 & 502 \\
\hline $\mathrm{Pr}_{6} \mathrm{O}_{11}$ & 141 & 0.0268 & 406 & 455 & 493 \\
\hline
\end{tabular}

calculated by integrating the corresponding peak areas with that of a standard sample (CuO). Almost all of the reduction peaks of the catalysts fall within the range of the soot oxidation temperature, belonging to $\mathrm{Ce}^{4+} \rightarrow \mathrm{Ce}^{3+}$ and $\mathrm{Pr}^{4+} \rightarrow \mathrm{Pr}^{3+}$. The OSC of $\mathrm{CeO}_{2}$ is greatly enhanced by introducing $\mathrm{Pr}$, which could provide more lattice oxygen, thereby leading to a higher combustion rate because of the further increase in the amount of available active oxygen. Particularly, CePr-NN shows a major reduction peak at $315{ }^{\circ} \mathrm{C}$, which is due to the formation of a solid solution

Table 2 Texture of the CePr catalysts with different structures

\begin{tabular}{|c|c|c|c|c|c|}
\hline Sample & $2 \theta$ & Lattice constant/nm & $\begin{array}{l}\text { Crystallite } \\
\text { size/nm }\end{array}$ & $S_{\mathrm{BET}} / \mathrm{m}^{2} \mathrm{~g}^{-1}$ & Lattice strain/\% \\
\hline $\mathrm{CeO}_{2}$ & 28.5458 & 0.5412 & 12.4 & 38.2200 & 1.113 \\
\hline CePr-NN & 28.4660 & 0.5426 & 10.4 & 24.9019 & 1.336 \\
\hline CePr-NO & 28.5328 & 0.5414 & 12.1 & 36.3385 & 1.148 \\
\hline CePr-ON & 28.4994 & 0.5420 & 10.1 & 23.9571 & 1.189 \\
\hline CePr-OO & 28.4660 & 0.5426 & 10.2 & 48.8569 & 1.305 \\
\hline $\operatorname{Pr}_{6} \mathrm{O}_{11}$ & 28.2784 & 0.8919 & 13.5 & 30.7774 & 1.034 \\
\hline
\end{tabular}




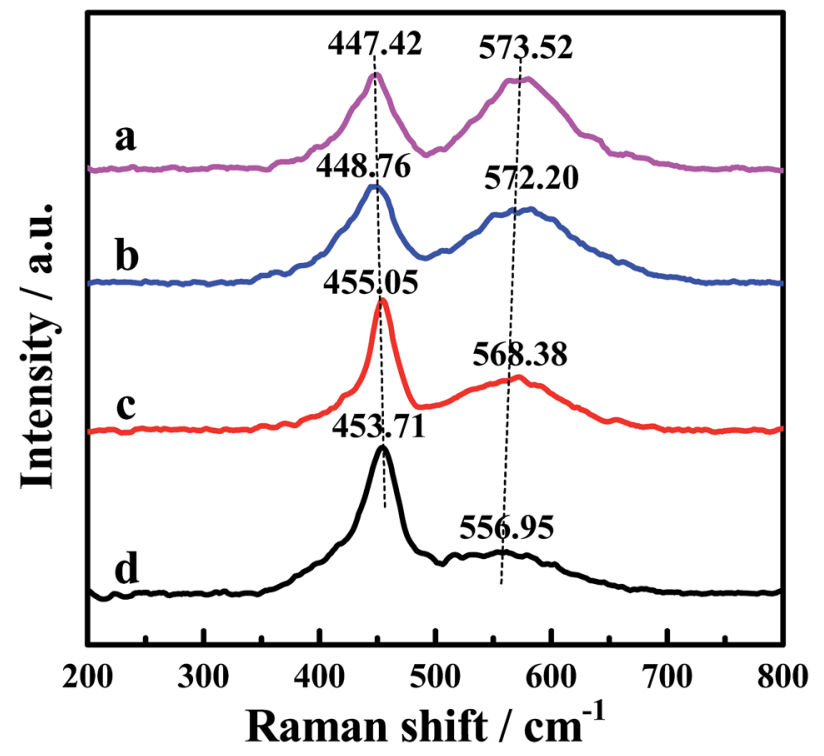

Fig. 4 Raman spectra of the CePr catalysts with different structures (a) CePr-NN; (b) CePr-NO; (c) CePr-ON; (d) CePr-OO.

Table 4 The value of $A_{570} / A_{450}$ deduced from Raman analysis

\begin{tabular}{llll}
\hline Sample & $A_{570} / A_{450}$ & Sample & $A_{570} / A_{450}$ \\
\hline CePr-NN & 1.744 & CePr-ON & 1.076 \\
CePr-NO & 1.470 & CePr-OO & 0.559
\end{tabular}

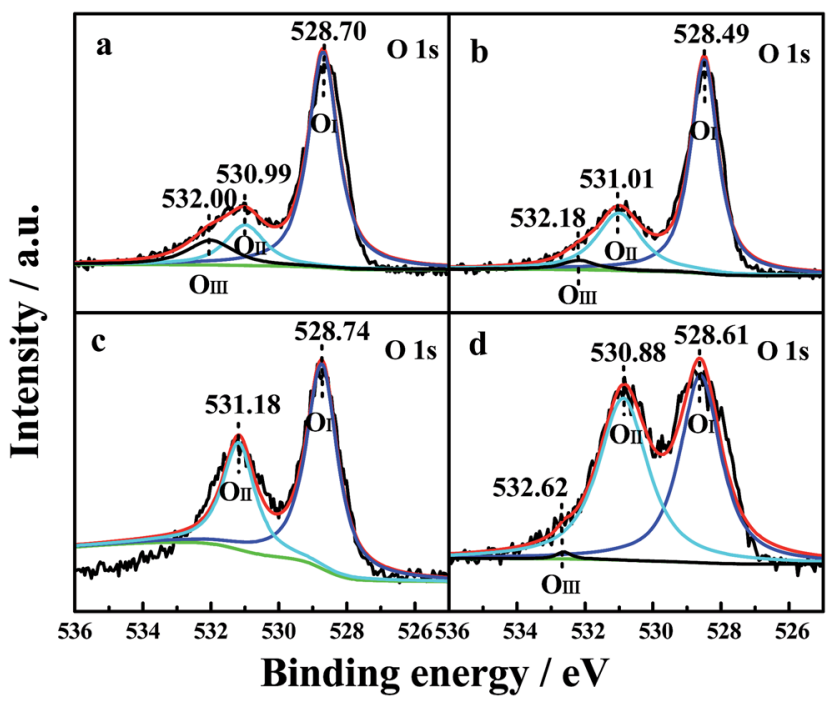

Fig. $5 \mathrm{O}$ 1s XPS profiles of the four CePr catalysts. (a) CePr-NN; (b) CePr-NO; (c) CePr-ON; (d) CePr-OO.

structure caused by the complete insertion of $\mathrm{Pr}$ into the $\mathrm{CeO}_{2}$ crystal lattice, and results in a significant improvement in OSC. Generally, the increased oxygen vacancies caused by the presence of Pr lead to easy exchange of oxygen. Therefore, the amount of reactive oxygen species can be increased and they are easily reduced by $\mathrm{H}_{2}$ at low temperature..$^{34,54}$
Table 5 Surface oxygen species percentage and surface chemical compositions of the CePr catalysts obtained from XPS

\begin{tabular}{llllll}
\hline Sample & $\mathrm{O}_{\mathrm{III}} / \%$ & $\mathrm{O}_{\mathrm{II}} / \%$ & $\mathrm{O}_{\mathrm{I}} / \%$ & $\mathrm{Ce} 3 \mathrm{~d} / \%$ & $\operatorname{Pr} 3 \mathrm{~d} / \%$ \\
\hline CePr-NN & 12.51 & 17.33 & 70.16 & 59.04 & 40.96 \\
CePr-NO & 3.47 & 29.05 & 67.48 & 51.19 & 48.81 \\
CePr-ON & - & 35.08 & 64.92 & 38.09 & 61.91 \\
CePr-OO & 0.65 & 50.79 & 48.56 & 35.85 & 64.15
\end{tabular}
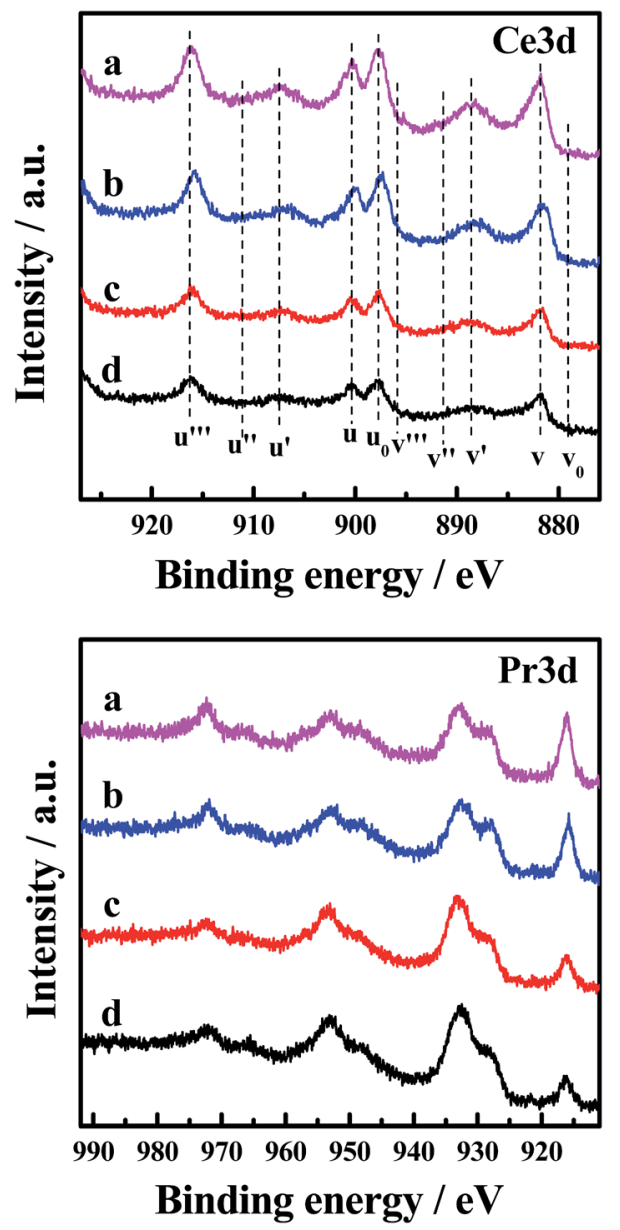

Fig. 6 Ce $3 d$ and $\operatorname{Pr} 3 d X P$ spectra of the four CePr catalysts. (a) CePrNN; (b) CePr-NO; (c) CePr-ON; (d) CePr-OO.

Two reduction peaks exist for CePr-NO, which simultaneously shift to lower temperatures compared with those of CePr-ON. $\mathrm{CeO}_{2}$ is believed to be the major active component in CePr catalysts, which is located on the surface, where reduction is easier. In combination with the XRD patterns, a solid solution structure is confirmed to be absent in the four kinds of CePr catalysts besides CePr-NN. Therefore, the good redox capacity at low temperature of these mixed oxides is mostly related to the synergy of $\mathrm{CeO}_{2}$ and $\mathrm{Pr}_{6} \mathrm{O}_{11}$.

In addition, as calculated from Table 3, 0.7 times the $\mathrm{H}_{2}$ consumption of $\mathrm{CeO}_{2}$ plus 0.3 times the $\mathrm{H}_{2}$ consumption of $\operatorname{Pr}_{6} \mathrm{O}_{11}$ is $0.028 \mathrm{~g}$. The value is less than that of CePr catalysts, implying that the delivery of oxygen capability increased 

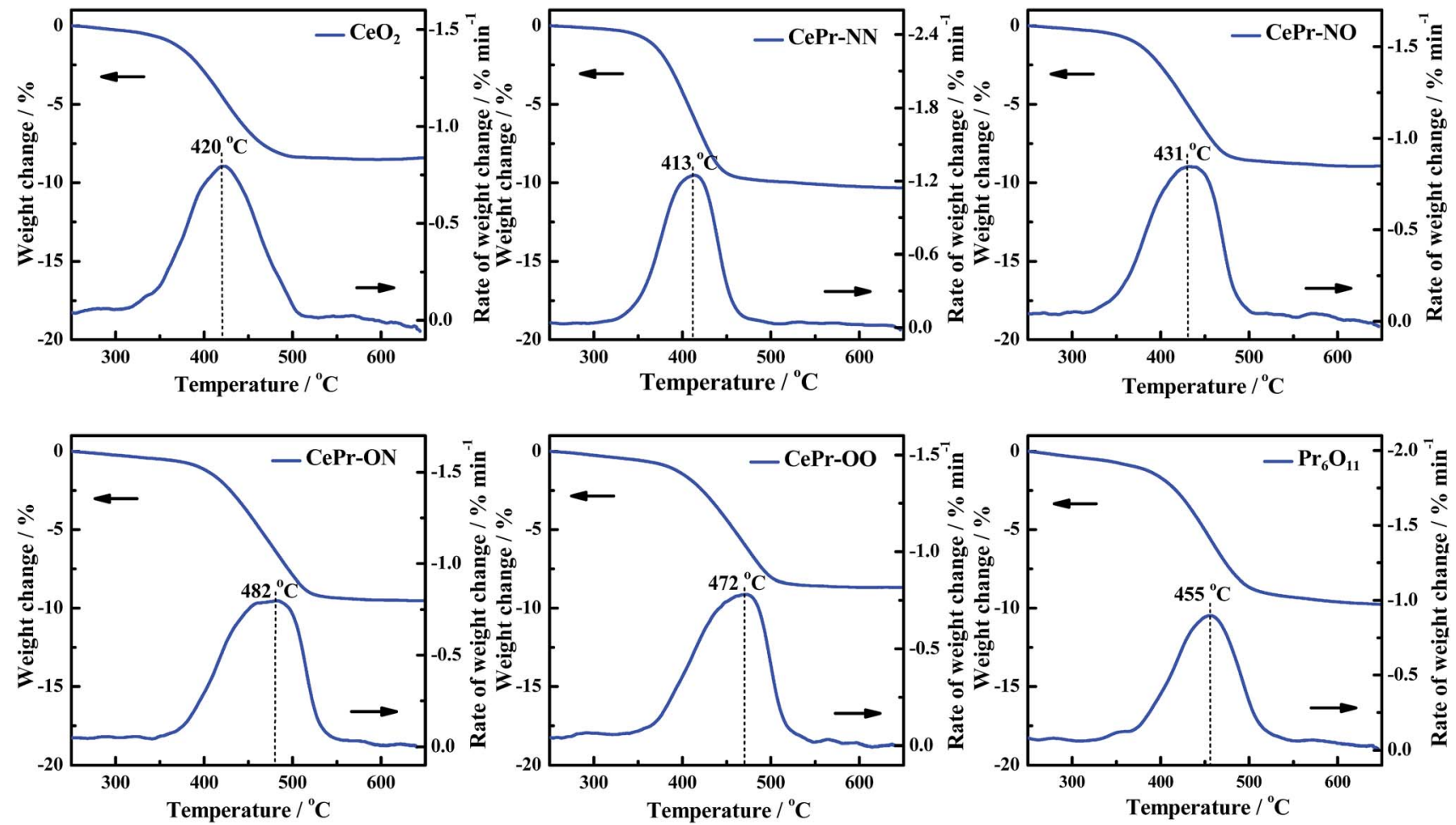

Fig. 7 TG and DTG curves of the soot/catalyst mixture with the CePr catalysts.

through the synergistic effect between $\mathrm{CeO}_{2}$ and $\operatorname{Pr}_{6} \mathrm{O}_{11}$, resulting in a good redox property.

The TPR results indicate that the solid solution structure is conducive to the production of more oxygen vacancies, improving the OSC of the CePr catalysts. Therefore, a more reactive oxygen species is proposed to be generated via the method of doping Pr with nitrate.
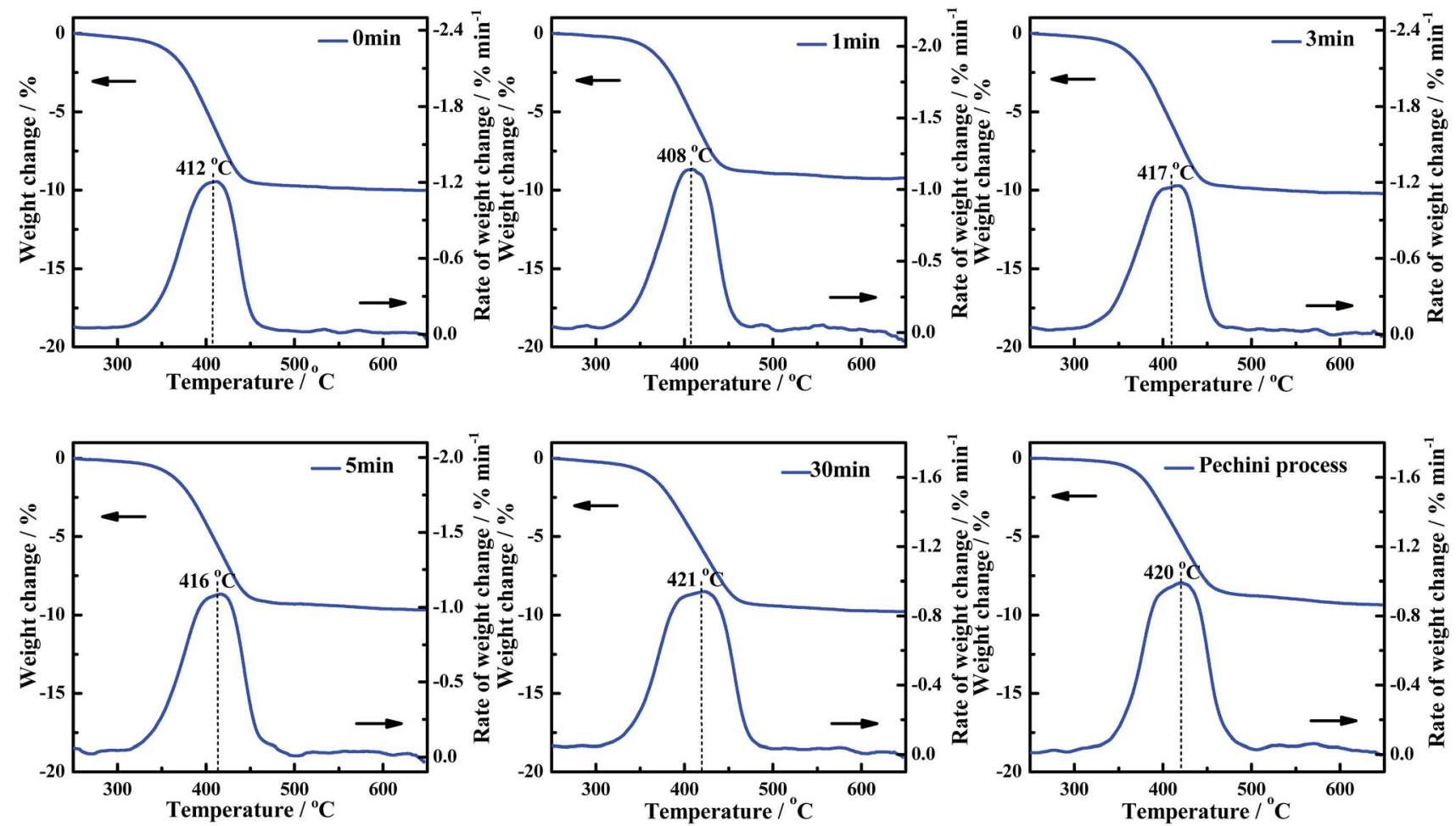

Fig. 8 TG and DTG curves of the soot/catalyst mixture for CePr-NN catalysts prepared with different grinding times. 
Table 6 Soot combustion on CePr-NN catalysts prepared with different grinding times

\begin{tabular}{|c|c|c|c|c|c|c|c|}
\hline Grinding time/min & $T_{\mathrm{i}} /{ }^{\circ} \mathrm{C}$ & $T_{\mathrm{m}} /{ }^{\circ} \mathrm{C}$ & $T_{\mathrm{f}} /{ }^{\circ} \mathrm{C}$ & Grinding time/min & $T_{\mathrm{i}} /{ }^{\circ} \mathrm{C}$ & $T_{\mathrm{m}} /{ }^{\circ} \mathrm{C}$ & $T_{\mathrm{f}} /{ }^{\circ} \mathrm{C}$ \\
\hline 0 & 365 & 412 & 438 & 5 & 365 & 416 & 445 \\
\hline 1 & 368 & 408 & 439 & 30 & 364 & 421 & 455 \\
\hline
\end{tabular}

\section{Oxygen vacancies}

The Raman spectra of the CePr catalysts with different structures are displayed in Fig. 4, the purpose of which is to demonstrate the formation of the oxygen vacancies. The Raman peak near $465 \mathrm{~cm}^{-1}$ is attributed to the $F_{2 g}$ Raman mode of $\mathrm{CeO}_{2}$, characteristic of a fluorite structured material. ${ }^{34,55-57}$ The band at $465 \mathrm{~cm}^{-1}$ shifts to a lower frequency, indicating the formation of the solid solution. ${ }^{32,34}$ Thus, the band shifted down to $447 \mathrm{~cm}^{-1}$ of CePr-NN suggests the formation of a CePr solid solution. Meanwhile, the peak at a Raman shift of $570 \mathrm{~cm}^{-1}$ corresponds to the presence of oxygen vacancies. ${ }^{34,56}$ Comparison of the Raman line shape in the four CePr mixed oxides shows that the incorporation of $\mathrm{Pr}$ ions into $\mathrm{CeO}_{2}$ must be accompanied by the generation of oxygen vacancies. The population of oxygen vacancies is proportional to the peak area

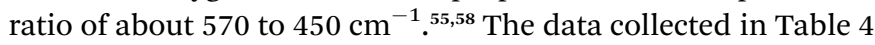
imply that there are more oxygen vacancies for CePr-NN than for the other three CePr catalysts, which is in agreement with the results of $\mathrm{H}_{2}$-TPR.

\section{Surface properties}

The oxidation states and surface composition of the catalysts were obtained by XPS analysis. The $\mathrm{O} 1 \mathrm{~s}$ spectra of the samples are shown in Fig. 5. The spectra show three types of oxygen species. The peak with a lower binding energy at 528.49$528.74 \mathrm{eV}$ was generally assigned to a normal $\mathrm{O} 1 \mathrm{~s}\left(\mathrm{O}_{\mathrm{I}}\right)$ signal that corresponds to the lattice oxygen type. The peak with a binding energy at 530.88-531.18 eV was attributed to oxygen species in the defects (denoted as $\mathrm{O}_{\mathrm{II}}$ ) (e.g. $, \mathrm{O}_{2}{ }^{-}, \mathrm{O}_{2}{ }^{2-}$ or $\mathrm{O}^{-}$), and the peak with a binding energy at 532.00-532.62 eV could instead be attributed to hydroxyl-like groups and adsorbed molecular water $\left(\mathrm{O}_{\text {III }}\right)^{5}$ The relative percentages of the three oxygen species were quantified based on the area ratios of their peaks (Table 5).
As observed from Table 5, the relative percentages of $\mathrm{O}_{\mathrm{II}}$ detected from CePr-NO, CePr-ON and CePr-OO were obviously higher than that of CePr-NN. However, the majority of the defect oxygen species of these three CePr catalysts might result from $\operatorname{Pr}_{6} \mathrm{O}_{11}$ on the surface of the catalysts. This should be due to the large reduction peak below $200{ }^{\circ} \mathrm{C}$ of $\operatorname{Pr}_{6} \mathrm{O}_{11}$. Obviously, these oxygen species do not work for the soot combustion reaction. This is because the oxygen release capacity of the catalysts in the range of $200{ }^{\circ} \mathrm{C}$ to $400{ }^{\circ} \mathrm{C}$ is responsible for the soot reaction. ${ }^{53}$ Combined with the results of the $\mathrm{H}_{2}$-TPR analysis, it is deduced that the defect oxygen species caused by $\operatorname{Pr}_{6} \mathrm{O}_{11}$ is the ineffective oxygen. Therefore, $\mathrm{CeO}_{2}$ is considered as the active phase in CePr catalysts. Only the CePr-NN with the highest $\mathrm{H}_{2}$ consumption between $200{ }^{\circ} \mathrm{C}$ and $400{ }^{\circ} \mathrm{C}$ possesses the most effective active oxygen. Generally, $\mathrm{O}_{\mathrm{II}}$ is responsible for oxidation reactions. ${ }^{5}$ It can be established that the essentiality of enough $\mathrm{O}_{\mathrm{I}}$ and $\mathrm{O}_{\mathrm{III}}$ required for supplemental effective active oxygen $\left(\mathrm{O}_{\mathrm{II}}\right)$ in the channel of oxygen migration $\left(\mathrm{O}_{\mathrm{I}} \leftrightarrow \mathrm{O}_{\mathrm{II}} \leftrightarrow\right.$ $\mathrm{O}_{\mathrm{III}}$ ) could be significant for the improvement of the OSC of the catalysts. Based on the above results, it can be concluded that CePr-NN showed the best catalytic activity and the fastest oxidation rate compared with the other three CePr catalysts, which might be attributed to its abundant oxygen species of $\mathrm{O}_{\mathrm{I}}$ and $\mathrm{O}_{\mathrm{III}}$.

The Ce 3d XP spectra and Pr 3d XP spectra of the catalysts are presented in Fig. 6. Meanwhile, the atomic concentrations of Ce and Pr at the surface of the catalysts are also shown in Table 5. The corresponding binding energies of Ce $3 \mathrm{~d}$ and Pr $3 \mathrm{~d}$ are not very different ( 870 and $970 \mathrm{eV}$, respectively). ${ }^{30}$ The main features of Ce $3 \mathrm{~d}$ are composed of ten peaks. The peaks labelled as $\mathrm{u}$ are due to corresponding $3 \mathrm{~d}_{3 / 2}$ spin-orbit states, and those labelled as $v$ are due to $3 d_{5 / 2}$ states. It can be seen from the spectrum that the four peaks labelled as $\mathrm{u}_{0}, \mathrm{u}^{\prime}, \mathrm{v}_{0}$ and $\mathrm{v}^{\prime}$ are attributed to $\mathrm{Ce}^{3+}$
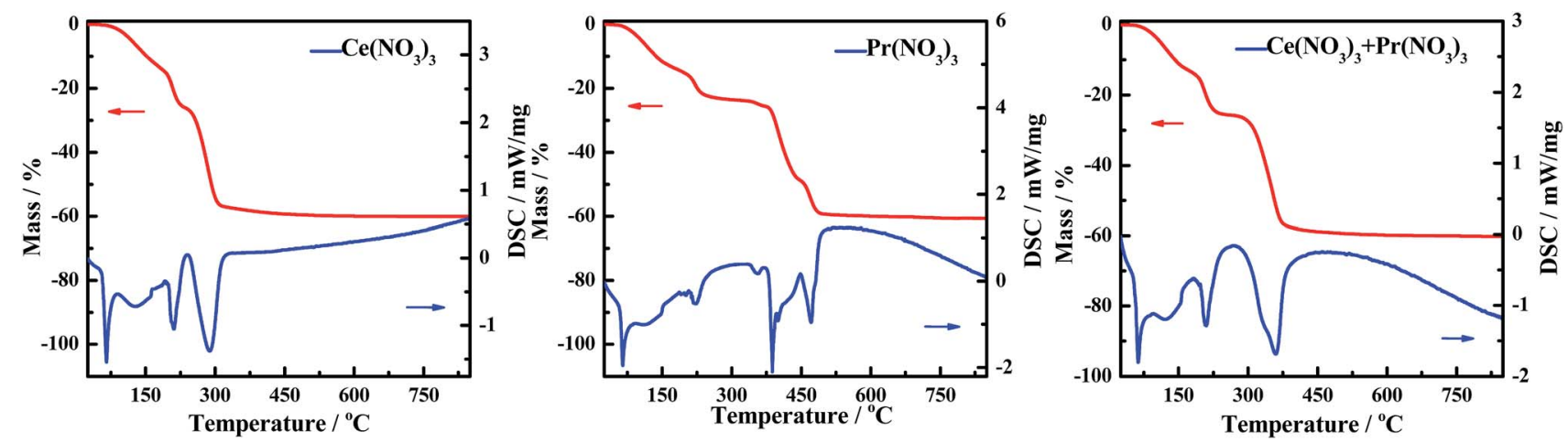

Fig. $9 \mathrm{TG}$ and DSC curves of $\mathrm{Ce}\left(\mathrm{NO}_{3}\right)_{3}, \operatorname{Pr}\left(\mathrm{NO}_{3}\right)_{3}$, and $\mathrm{Ce}\left(\mathrm{NO}_{3}\right)_{3}+\operatorname{Pr}\left(\mathrm{NO}_{3}\right)_{3}$. 


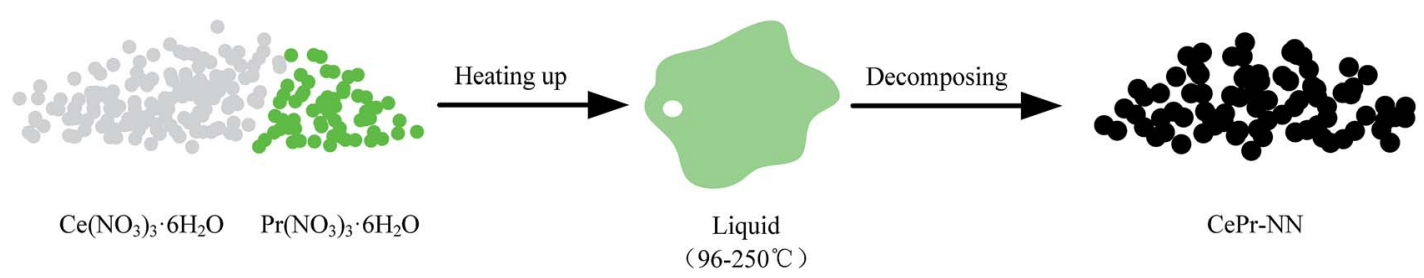

Fig. 10 A schematic drawing of the formation and disappearance of the molten state.

ions, and the other peaks labelled as $\mathrm{u}, \mathrm{u}^{\prime \prime}, \mathrm{u}^{\prime \prime \prime}, \mathrm{v}, \mathrm{v}^{\prime \prime}$ and $\mathrm{v}^{\prime \prime \prime}$ are related to $\mathrm{Ce}^{4+}$ ions. ${ }^{5}$ Analysis of the spectra indicates that in the CePr mixed oxides cerium is present in both the $3+$ and $4+$ oxidation states, with the major oxidation state being $4+$. Moreover, the relative intensity of the two peaks annotated $\mathrm{u}^{\prime}$ and $\mathrm{v}^{\prime}$ of CePr-NN is more prominent than for the other three catalysts, indicating that the incorporation of $\mathrm{Pr}^{4+}$ results in more surface $\mathrm{Ce}^{3+}$ in the solid solution structure. The existence of $\mathrm{Ce}^{3+}$ in the $\mathrm{CeO}_{2}$ lattice implies the formation of oxygen vacancies. ${ }^{31}$ Furthermore, the higher the $\mathrm{Ce}^{3+}$ concentration of the total Ce that exists, the more oxygen vacancies there are.

\section{Catalyst activity in soot combustion}

The activity measurements of the CePr catalysts for soot oxidation were investigated under an $\mathrm{O}_{2} / \mathrm{N}_{2}$ atmosphere under "tight contact" conditions and are presented in Fig. 7. Generally, this analysis is used to discriminate the catalysts in terms of their intrinsic activity. ${ }^{3}$ The catalytic activities of the four kinds of CePr catalysts are compared using the reaction temperatures referred to as $T_{\mathrm{i}}, T_{\mathrm{m}}$, and $T_{\mathrm{f}}$ (Table 3). Obviously, CePr-NN gave the best low-temperature catalytic activity among the CePr catalysts, followed by CePr-NO, CePr-OO and CePr-ON. CePr-NN exhibits a similar catalytic activity to $\mathrm{CeO}_{2} ; \mathrm{CeO}_{2}$ presents a higher activity than the three other CePr catalysts. This finding indicates that $\mathrm{CeO}_{2}$ is the major active component of the CePr mixed oxides. Therefore, the greater amount of $\mathrm{CeO}_{2}$ exposed on the catalyst surface results in a higher activity of soot oxidation.

Combined with the XRD results, the higher combustion rate of CePr-NN compared with that of pure $\mathrm{CeO}_{2}$ is caused by the presence of a solid solution structure with a smaller crystal size
Table 7 Thermal stability comparison of $\mathrm{CeO}_{2}$ and $\mathrm{CePr}-\mathrm{NN}$ catalysts

\begin{tabular}{lccclccc}
\hline Sample & $T_{\mathrm{i}} /{ }^{\circ} \mathrm{C}$ & $T_{\mathrm{m}} /{ }^{\circ} \mathrm{C}$ & $T_{\mathrm{f}} /{ }^{\circ} \mathrm{C}$ & Sample & $T_{\mathrm{i}} /{ }^{\circ} \mathrm{C}$ & $T_{\mathrm{m}} /{ }^{\circ} \mathrm{C}$ & $T_{\mathrm{f}} /{ }^{\circ} \mathrm{C}$ \\
\hline $\mathrm{CeO}_{2}-\mathrm{F}$ & 370 & 420 & 467 & $\mathrm{CeO}_{2}-\mathrm{A}$ & 452 & 548 & 599 \\
$\mathrm{Pr}_{6} \mathrm{O}_{11}-\mathrm{F}$ & 406 & 455 & 493 & $\mathrm{Pr}_{6} \mathrm{O}_{11}-\mathrm{A}$ & 438 & 503 & 544 \\
CePr-NN-F & 370 & 413 & 443 & CePr-NN-A & 388 & 443 & 470
\end{tabular}

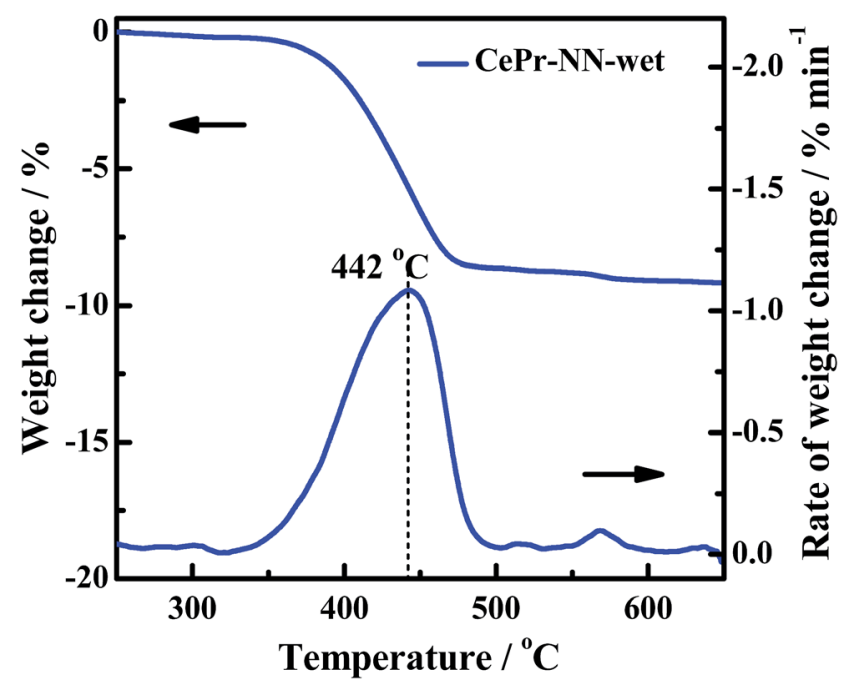

Fig. 12 The catalytic activity of CePr-NN after wet atmosphere treatment.

and more defects, which could be beneficial to improve the OSC. In combination with the $\mathrm{H}_{2}$-TPR profiles, the reducibility of the CePr catalysts basically presents regularity on the soot
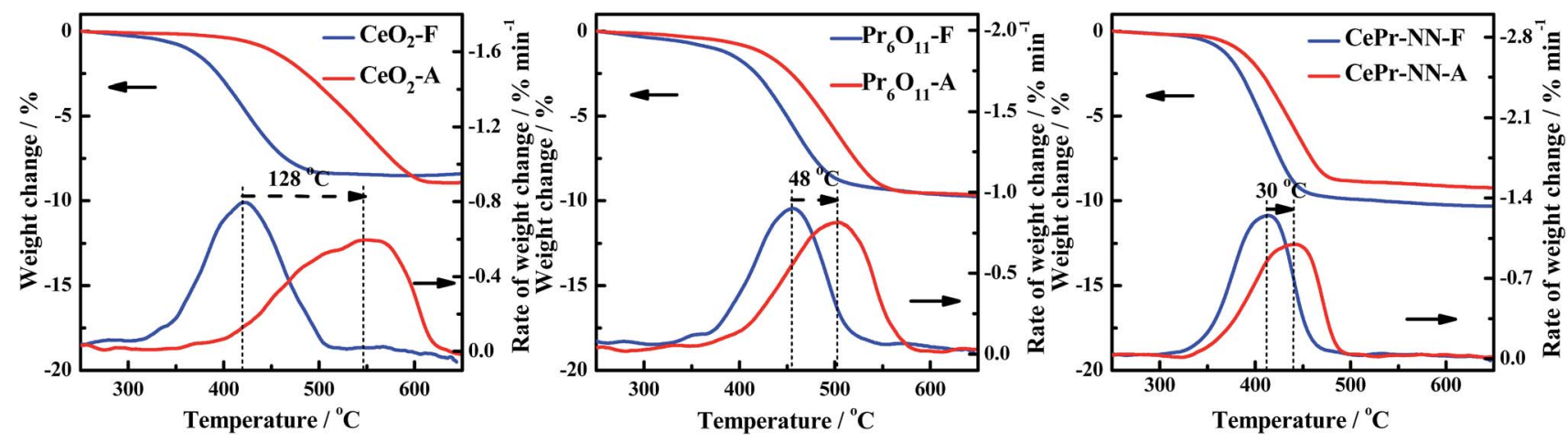

Fig. 11 TG and DTG curves of the soot/catalyst mixture. 


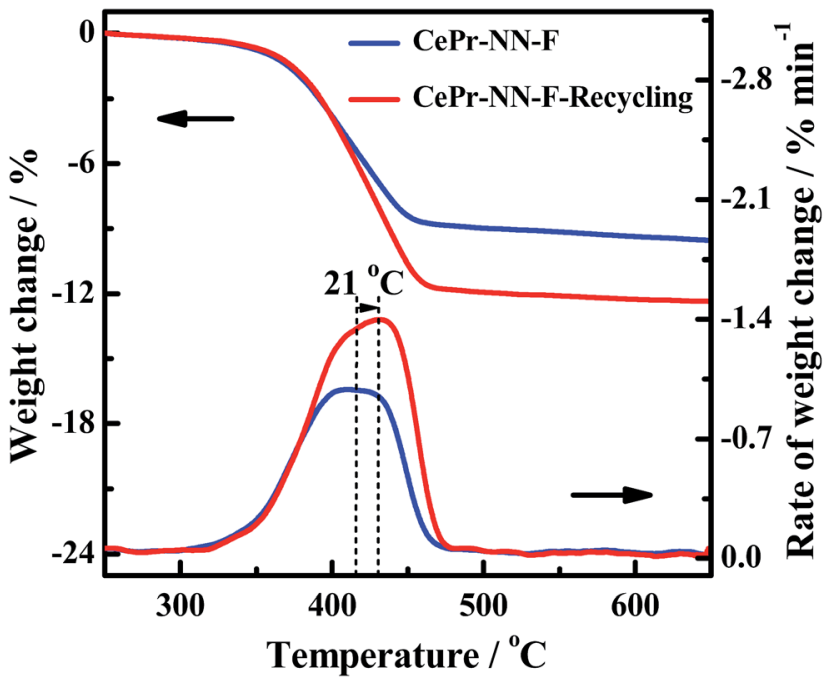

Fig. 13 The recycling of the CePr-NN for soot combustion.

combustion activity; in other words, a larger $\mathrm{H}_{2}$ consumption means a better catalytic activity. In addition, the small reduction peaks of CePr-ON and CePr-OO suggest that there are few surface oxygen species, which provide results at $30{ }^{\circ} \mathrm{C}$ to $40{ }^{\circ} \mathrm{C}$, increasing the ignition temperature. However, the large amount of high-temperature lattice oxygen is not sufficient for soot oxidation, leading to the burnout temperature being above $500{ }^{\circ} \mathrm{C}$.

If one focuses on the ignition temperature of CePr-NN, reduction is not obtained as it is with pure $\mathrm{CeO}_{2}$, but the rate of catalytic combustion is accelerated because of $\Delta T=T_{\mathrm{f}}-T_{\mathrm{i}}$ (the difference between the ignition temperature and burnout temperature). This means that the solid solution structure is beneficial for the enhancement of the soot oxidation rate. This reaction is caused by the large number of active oxygen species with high density and high mobility in the low-temperature range. In conclusion, CePr catalysts with different structures prepared from different precursors directly affect the soot combustion performance.

\section{Grinding times for CePr-NN}

The influence of uniformity (grinding times) in the solid-phase grinding method is studied. The activities of the CePr-NN catalysts prepared with different grinding times were measured, and are shown in Fig. 8. The corresponding reaction temperatures $\left(T_{\mathrm{i}}, T_{\mathrm{m}}\right.$ and $\left.T_{\mathrm{f}}\right)$ are presented in Table 6 to compare the catalytic activities. The $T_{\mathrm{i}}$ values vary in a significantly narrow range $\left(364{ }^{\circ} \mathrm{C}\right.$ to $\left.368^{\circ} \mathrm{C}\right)$ as the grinding time increases, indicating a similar low-temperature catalytic activity for all of the CePr-NN catalysts. The catalytic activity did not increase with the increase of uniformity compared with that of CePr prepared by Pechini process.

The experiments point out that the grinding time does not affect the activity of CePr-NN for soot combustion. Thus, highactivity CePr catalysts can be prepared without prolonged grinding. However, the activity of the CePr-NN catalyst being independent from the grinding time remains unclear. Thus, nitrates were studied directly by means of TG to observe the change of states in the heating process.

The DSC curves corresponding to any changes in the heat of CePr-NN are shown in Fig. 9. A considerable amount of heat was absorbed during the sequential loss in both physical and hydrated water, as well as thermal decomposition process of the nitrates. ${ }^{59-61}$ Fig. 10 shows that solid turns into liquid ("molten state") when nitrates reach their melting points $\left(96{ }^{\circ} \mathrm{C}\right.$ for cerium nitrate and $56{ }^{\circ} \mathrm{C}$ for praseodymium nitrate) with increasing temperature. The molten state is present until the nitrates completely decomposed into our catalyst. Therefore, we suggest that $\mathrm{Ce}^{4+}$ and $\operatorname{Pr}^{4+}$ migrate quickly to accomplish mixing, which could occur instead of grinding in this process. In addition, heat absorbed during $\mathrm{NO}_{3}{ }^{-}$decomposition also plays an important role in $\mathrm{Ce}^{4+}$ and $\operatorname{Pr}^{4+}$ migration.

In this regard, the existence of the molten state is an important factor for preparing CePr catalysts with different structures. Particularly, the high catalytic activity of CePr-NN is mainly attributed to the formation of a solid solution structure. Thus, for soot combustion, the grinding time is not considered to be important, which means that high activity catalysts can be prepared without grinding when nitrates are used as precursors.

\section{Thermal stability test}

The thermal stability was therefore examined because CePr-NN exhibits the same good catalytic activity as pure $\mathrm{CeO}_{2}$ toward soot combustion. To prove that the catalytic performance of CePr-NN is better than that of $\mathrm{CeO}_{2}$ in soot oxidation, the thermal stability of the catalysts was characterized by calcining at $800{ }^{\circ} \mathrm{C}$ for $10 \mathrm{~h}$ (marked as $\mathrm{A}$ ) and compared with the catalytic activity at $500{ }^{\circ} \mathrm{C}$ for $10 \mathrm{~h}$ (marked as F).

Fig. 11 shows the TG and DTG curves for soot combustion for the fresh and aging samples of $\mathrm{CeO}_{2}$, CePr-NN, and $\operatorname{Pr}_{6} \mathrm{O}_{11}$. The measured values of $T_{\mathrm{i}}, T_{\mathrm{m}}$, and $T_{\mathrm{f}}$ from the DTG are listed in Table 7. As shown in Fig. 11, both $\mathrm{CeO}_{2}$ and CePr-NN demonstrate good activity at $500{ }^{\circ} \mathrm{C}$. The thermal stability test performed at $800{ }^{\circ} \mathrm{C}$ shows that the soot combustion is faster in the case of CePr-NN compared with that of $\mathrm{CeO}_{2}$, for which the activity decreased sharply with serious sintering. $T_{\mathrm{i}}$ did not increase remarkably with respect to the fresh sample, indicating that CePr-NN has good thermal stability. Note that $\operatorname{Pr}_{6} \mathrm{O}_{11}$ shows high stability, and the supporting phase, Pr, is thus concluded to enhance both the combustion rate and thermal stability of the catalyst toward soot oxidation.

The gas composition is complex in engine exhausts, and includes $\mathrm{H}_{2} \mathrm{O}, \mathrm{CO}_{x}, \mathrm{NO}_{x}$ and $\mathrm{HC}$. The soot oxidation reaction may be affected by these gases. Previous research and literature have shown that $\mathrm{NO}_{x}$ is a powerful oxidant, ${ }^{17}$ which is conducive to a significant decrease in the soot oxidation temperature; $\mathrm{H}_{2} \mathrm{O}$ may also affect the activity structure of the catalyst. Therefore, an experiment of treatment of CePr-NN-F at $850{ }^{\circ} \mathrm{C}$ in a wet atmosphere (100\% relative humidity) for a couple of hours has been shown (Fig. 12). After treatment with steam, the activity of the catalyst is close to that of CePr-NN-A, which exhibits $T_{\mathrm{i}}, T_{\mathrm{m}}$ 
and $T_{\mathrm{f}}$ values of 395,444 and $467^{\circ} \mathrm{C}$, respectively. This indicated that CePr-NN-F exhibits good stability in the presence of steam.

In order to further verify the reuse of the CePr-NN catalyst, a recycling experiment has been conducted. The residual CePrNN catalyst which has burned soot in the crucible was mixed with soot particles (catalyst : soot $=1: 10$ ), and then the catalytic activity of the catalyst was studied in the TG analyzer again, the results of which are shown in Fig. 13. It can be seen that CePr-NN has an excellent recyclability, illustrating that CePr-NN could maintain a stable active structure in the reaction.

\section{Conclusions}

Incorporation of $\mathrm{Pr}$ atoms into $\mathrm{CeO}_{2}$ with nitrates as precursors mainly improves its OSC and the mobility of active oxygen at $200{ }^{\circ} \mathrm{C}$ to $400{ }^{\circ} \mathrm{C}$, which leads to a higher combustion rate without affecting the soot ignition temperature. In addition, doping $\mathrm{CeO}_{2}$ with Pr can greatly enhance its thermal stability, because highly stable $\operatorname{Pr}_{6} \mathrm{O}_{11}$ is used as the supporting phase of the catalyst for soot oxidation. The molten state appeared during the preparation when nitrate is used as the precursor, and the heat absorbed when $\mathrm{NO}_{3}{ }^{-}$decomposed plays an important role in the migration of $\mathrm{Ce}$ and Pr. Subsequently, CePr catalysts with different structures are formed, whose activities are independent of the grinding time. Particularly, CePr-NN with a solid solution structure exhibits an accelerated combustion rate and high thermal stability for soot combustion.

\section{Acknowledgements}

We would like to acknowledge the financial support from the Natural Science Foundation of China (No. 21506194, 21676255), Zhejiang Provincial Natural Science Foundation of China (No. Y14E080008, Y16B070025).

\section{Notes and references}

1 B. R. Stanmore, J. F. Brilhac and P. Gilot, Carbon, 2001, 39, 2247-2268.

2 Y. Q. Sheng, Y. Zhou, H. F. LU, Z. K. Zhang and Y. F. Chen, Chin. J. Catal., 2013, 34, 567-577.

3 P. A. Kumar, M. D. Tanwar, S. Bensaid, N. Russo and D. Fino, Chem. Eng. J., 2012, 207-208, 258-266.

4 D. Fino, S. Bensaid, M. Piumetti and N. Russo, Appl. Catal., A, 2016, 509, 75-96.

5 P. Venkataswamy, D. Jampaiah, K. N. Rao and B. M. Reddy, Appl. Catal., A, 2014, 488, 1-10.

6 Q. Shen, M. F. Wu, H. Wang, C. He, Z. P. Hao, W. Wei and Y. H. Sun, Catal. Sci. Technol., 2015, 5, 1941-1952.

7 L. Katta, P. Sudarsanam, G. Thrimurthulu and B. M. Reddy, Appl. Catal., B, 2010, 101, 101-108.

8 J. Giménez-Mañogil and A. García-García, Fuel Process. Technol., 2015, 129, 227-235.

9 E. Aneggi, N. J. Divins, C. D. Leitenburg, J. Llorca and A. Trovarelli, J. Catal., 2014, 312, 191-194.

10 M. Haneda and A. Towata, Catal. Today, 2015, 242, 351-356.
11 G. C. Zou, Y. Xu, S. J. Wang, M. X. Chen and W. F. Shangguan, Catal. Sci. Technol., 2015, 5, 1084-1092.

12 E. Aneggi, C. D. Leitenburg and A. Trovarelli, Catal. Today, 2012, 181, 108-115.

13 H. L. Zhang, Y. Zhu, S. D. Wang, M. Zhao, M. C. Gong and Y. Q. Chen, Fuel Process. Technol., 2015, 137, 38-47.

14 A. Bueno-López, Appl. Catal., B, 2014, 146, 1-11.

15 M. Shelef and R. W. McCabe, Catal. Today, 2000, 62, 35.

16 R. M. Heck and R. J. Farrauto, Appl. Catal., A, 2001, 221, 443.

17 S. Liu, X. D. Wu, D. Weng and R. Ran, J. Rare Earths, 2015, 33, 567-590.

18 C. Lee, J. I. Park, Y. G. Shul, H. Einaga and Y. Teraoka, Appl. Catal., B, 2015, 174-175, 185-192.

19 A. Bueno-López, K. Krishna, M. Makkee and J. A. Moulijn, Catal. Lett., 2015, 99, 203-205.

20 P. Palmisano, N. Russo, D. Fino and C. Badini, Appl. Catal., B, 2006, 69, 85-92.

21 C. B. Lim, H. Kusaba, H. Einaga and Y. Teraoka, Catal. Today, 2011, 175, 106-111.

22 M. L. Fu, X. H. Yue, D. Q. Ye, J. H. Ouyang, B. C. Huang, J. L. Wu and H. Liang, Catal. Today, 2010, 153, 125-132.

23 H. Muroyama, S. Hano, T. Matsui and K. Eguchi, Catal. Today, 2010, 153, 133-135.

24 M. Dhakad, T. Mitshuhashi, S. Rayalu, P. Doggali, S. Bakardjiva, J. Subrt, D. Fino, H. Haneda and N. Labhsetwar, Catal. Today, 2008, 132, 188-193.

25 M. A. Małecka, L. Kępiński and W. Miśta, Appl. Catal., B, 2007, 74, 290-298.

26 K. Harada, T. Oishi, S. Hamamoto and T. Ishihara, J. Phys. Chem. C, 2014, 118, 559-568.

27 H. Muroyama, H. Asajima, S. Hano, T. Matsui and K. Eguchi, Appl. Catal., A, 2015, 489, 235-240.

28 L. F. Nascimento, R. F. Martins, R. F. Silva, P. C. de Sousa Filho and O. A. Serra, React. Kinet. Catal. Lett., 2014, 111, 149-165.

29 E. Saab, S. Aouad, E. Abi-Aad, E. Zhilinskaya and A. Aboukaïs, Catal. Today, 2007, 119, 286-290.

30 B. de Rivas, N. Guillén-Hurtado, R. López-Fonseca, F. Coloma-Pascual, A. García-García, J. I. Gutiérrez-Ortiz and A. Bueno-López, Appl. Catal., B, 2012, 121-122, 162-170.

31 G. Thrimurthulu, K. N. Rao, D. Devaiah and B. M. Reddy, Res. Chem. Intermed., 2012, 38, 1847-1855.

32 N. Guillén-Hurtado, A. García-García and A. Bueno-López, Appl. Catal., B, 2015, 174-175, 60-66.

33 P. Fang, M. F. Luo, J. Q. Lu, S. Q. Cen, X. Y. Yan and X. X. Wang, Thermochim. Acta, 2008, 478, 45-50.

34 V. Rico-Pérez, E. Aneggi, A. Bueno-López and A. Trovarelli, Appl. Catal., B, 2016, 197, 95-104.

35 V. Rico-Pérez and A. Bueno-López, Chem. Eng. J., 2015, 279, 79-85.

36 L. Katta, P. Sudarsanam, G. Thrimurthulu and B. M. Reddy, Appl. Catal., B, 2010, 101, 101-108.

37 J. Liu, Z. Zhao, C. M. Xu, A. J. Duan, L. Wang and S. J. Zhang, Catal. Commun., 2007, 8, 220-224.

38 G. Z. Zhang, Z. Zhao, J. F. Xu, J. X. Zheng, J. Liu, G. Y. Jiang, A. J. Duan and H. He, Appl. Catal., B, 2011, 107, 302-315. 
39 I. Atribak, B. Azambre, A. Bueno López and A. García-García, Appl. Catal., B, 2009, 92, 126-137.

40 M. Piumetti, S. Bensaid, N. Russo and D. Fino, Appl. Catal., $B, 2015,165,742-751$.

41 P. Miceli, S. Bensaid, N. Russo and D. Fino, Chem. Eng. J., 2015, 278, 190-198.

42 K. Nakagawa, T. Ohshima, Y. Tezuka, M. Katayama, M. Katoh and S. Sugiyama, Catal. Today, 2015, 246, 67-71.

43 C. F. Oliveira, F. A. C. Garcia, D. R. Araújo, J. L. Macedo, S. C. L. Dias and J. A. Dias, Appl. Catal., A, 2012, 413-414, 292-300.

44 L. F. Nascimento, R. F. Martins and O. A. Serra, J. Rare Earths, 2014, 7, 610-620.

45 M. A. Małecka, Ceram. Int., 2016, 42, 14826-14833.

46 H. F. Lu, X. X. Kong, H. F. Huang, Y. Zhou and Y. F. Chen, J. Environ. Sci., 2015, 32, 102-107.

47 Y. Zhou, C. J. Xu, Y. Q. Sheng, Q. L. Zhu, Y. F. Chen and H. F. Lu, RSC Adv., 2015, 5, 91734-91741.

48 H. F. Lu, Y. Zhou, H. F. Huang, B. Zhang and Y. F. Chen, J. Rare Earths, 2011, 9, 855-860.

49 N. J. Feng, J. Meng, Y. Wu, C. Chen, L. Wang, L. Gao, H. Wan and G. F. Guan, Catal. Sci. Technol., 2016, 6, 2930-2941.

50 J. G. Wang, L. Cheng, W. An, J. L. Xu and Y. Men, Catal. Sci. Technol., 2016, 6, 7342-7350.
51 W. F. Shangguan, Y. Teraoka and S. Kagawa, Appl. Catal., B, 1997, 12, 237-247.

52 Z. P. Wang, Z. X. Zhang and W. F. Shangguan, Chem. Res. Chin. Univ., 2009, 30, 2226-2232.

53 G. Mul, F. Kapteijn and J. A. Moulijn, Appl. Catal., B, 1997, $12,33-47$.

54 M. F. Luo, Z. L. Yan and L. Y. Jin, J. Mol. Catal. A: Chem., 2006, 260, 157-162.

55 Y. J. Luo, K. C. Wang, Y. X. Xu, X. Y. Wang, Q. R. Qian and Q. H. Chen, New J. Chem., 2015, 39, 1001-1005.

56 J. E. Spanier, R. D. Robinson, F. Zhang, S.-W. Chan and I. P. Herman, Phys. Rev. B: Condens. Matter Mater. Phys., 2001, 245-407, 1-8.

57 V. G. Keramidas and W. B. White, J. Chem. Phys., 1973, 59, 1561-1562.

58 Q. Liang, X. D. Wu, D. Weng and H. B. Xu, Catal. Today, 2008, 139, 113-118.

59 M. Karppinen, P. Kylgikoski, L. Niinist and C. Rodellas, J. Therm. Anal., 1989, 35, 347-353.

60 A. Malecki, A. Malecka, R. Gajerski, B. Prochowska-Klisch and A. Podgórecka, J. Therm. Anal., 1988, 34, 203-209.

61 K. T. Wojciechowski and A. MaIecki, Thermochim. Acta, 1999, 331, 73-77. 